aggravate the situation; whether it plays any significant role in lowering the plasma level is very doubtful.

The second point is more important-the suggestion that epileptic women on anticonvulsant drugs should not be given folic acid supplements during pregnancy unless "megaloblastic anaemia actually occurs," because of a risk of increased fits. The clinical evidence for an increase in fits following folic acid supplements in epilepsy has been disputed. But on the other hand there seems no doubt that anticonvulsants can provoke a measure of folate deficiency, which may not necessarily develop into overt megaloblastic anaemia. The dilemma becomes particularly acute with anticonvulsant therapy duning pregnancy. The possibility of a lower fit threshold must be balanced against the potential hazands to mother and fetus of some insidious disturbance of folate metabolism. Until we know much more about the complex metabolic inter-relations of folate and anticonvulsant drugs, particularly in pregnancy, Dr. Hall's advice seems a little injudicious.-We are, etc.,

M. J. LANDON F. E. HYTTEN

M.R.C. Reproduction and Growth Unit,

Princess Mary Maternity Hospital,

Newcastle upon Tyne 1 Landon, M. J., and Hytten, F. E., fournal of

Obstetrics and Gynaecology
Commonwealth, 1971, 78, 769.

\section{Death during Dental Anaesthesia}

SIR,-Dr. J. G. Boume (16 March, p. 516) has undoubtedly done a useful service in drawing attention to the dangers of fainting in the dental chair. I have given between 400 and 800 dental anaesthetics annually, the great majority in the $45^{\circ}$ sitting position, for the past 30 years. In this time, however, I have only once observed a faint before or during anaesthesia, and this, as in Dr. W. N. Rollason's case (25 May, p. 444), occurred on venepuncture and before the injection of an intravenous anaesthetic. The occasional patient has, of course, shown a vasovagal response to a postoperative nausea or vomit, but none has proceeded to unconsciousness and all have responded promptly to treatment.

This experience prompts me to ask why I have been more fortunate than some others. It may be that the circumstances of private practice are, in some respects, more favourable than outpatient clinics. The patients generally know the dentist well and may also know me, the anaesthetist, perconally. The sessions are short, usually three to five cases, and by having them in the early morning the patients are not hanging about a large part of the day with nothing in their bellies. It is unusual for them to be kept longer than a few minutes in the waiting room. Consequently it is rare for them to come to op ration looking pale and frightened, and when they do extra care is taken.

In short, what strikes me most about these difficult cares is the presence of pathological fear. If this is protracted (and, maybe, aggravated by pain and toxic absorption) we have a situation in which the patient's adrenocortical response mechanism is exhausted before it is confronted with anaesthetic or surgical insults. This, I believe, is of greater significance than either the particular anaesthetic technique, or the agents used-provided of course that they are correctly applied-or indeed the exact position of the patient in the dental chair.

While not disputing the potential added safety of the horizontal position, therefore, I wonder whether stressing it is not putting the accent in the wrong place. Would it not be as well to teach (1) that greater efforts should be made to protect patients from the stresses which lead to a fainting reaction and (2) that pale and frightened patients are very special risk patients who need extra care in their management?-I am, etc.,

Stratford-upon-Avon

E. O. Evans

\section{Cremophor EL as a Diluent for Diazepam}

SIR,-Diazepam has proved a safe and reliable drug though there have been many reports of minor sequelae after intravenous administration. Pain during injection has been reported in $15 \%$ to $22 \%$ of patients ${ }^{12}$ and a $3.5 \%$ to $30 \%$ incidence of postoperative venous thrombosis or thrombophlebitis has been found. ${ }^{3}$ There seems to be no correlation between pain during injection and postoperative venous sequelae. ${ }^{3}$

Dilution of diazepam with water or saline reduces the incidence of these side effects ${ }^{4}$ but an emulsion of fine particles is produced. ${ }^{5}$ We have found that, if freshly prepared, these emulsions will clear when mixed with an equal volume of serum. However, if the emulsion is allowed to stand for a short time solid crystals which are insoluble in serum gradually form. It would therefore seem that the intravenous injection of such emulsions presents a potential hazard. Cremophor EL has the ability to take into solution a variety of agents which themselves are only sparingly soluble in water, a $20 \%$ solution being used in preparations of both propanidid and Althesin. We have found that when diazepam is diluted with a $1 \%$ solution of cremophor EL no clouding or precipitation occur. The mixture is stable for some time and it does not form a precipitate when added to serum. Though cremophor EL appears to be a safe organic solven $t^{6}$ possibly it may very occasionally be reponsible for adverse reactions in susceptible subjects. In view of this we are a present studying the use of a $10 \%$ mixture of ethanol in saline as an alternative diluent.

Over the past two years we have used $1 \%$ solution of cremophor EL in saline as a diluent for diazepam given intravenously in over 400 patients. Before use the cremophor solution was filtered, put into ampoules, and autoclaved: $8 \mathrm{ml}$ of the solution was used to dilute $2 \mathrm{ml}$ of diazepam, giving a mixture containing $1 \mathrm{mg} / \mathrm{ml}$. Use of this mixture has practically eliminated the incidence of pain during iniection, even when into small veins on the back of the hand. Pos operative venous thrombosis and thrombophlebitis occurred in fewer that $1 \%$ of patients.-We are, etc.,

G. W. Burton R. T. LENZ

Bristol Royal Infirmary

T. A. THOMAS

University Dental Hospital,

M. MIDDA

1 Brown, S. S., and Dundee, J. of Anaesthesia, 1968, 40, 108.
Moclish, A., Canadian Anaesthetists' Society
fournal, 1966, 13, 562.
3 Langdon, D. E., Harlan, J. R., and Bailey, R. L.,
fournal of the American Medical Association,
1973, 223, 184.
4 Hunter, A. R., and Bush, G. H., General
Anaesthesia for Dental Surgery, p. 95. Altrin-
cham, Sherratt, 1971.
5 Dundee, J. W., and Haslett, W. H. K., British
fournal of Anaesthesia, 1970, 42, 217
6 Savage, T. M., Foley, E. I., and Simpson, B. R.,
British fournal of Anaesthesia, 1973, 45, 515.

Flupenthixol Decanoate and Some Aggressive States

SIR,-There is no reference in the English medical literature to the use of flupenthixol in remote reactions. Because neuroleptic drugs as a group have sedative properties of a special order I gave flupenthixol decanoate to six patients in doses of 10-12 mg fortnightly by deep intramuscular injection. The patients all had a common factor-extremely low tolerance to frustration. Their reaction to this was either a sudden outburst of rage or the development of sullen hate with a later manifestation of aggression against the object that had induced the complex mood.

They all benefited with a marked reduction of the underlying anxiety and cessation of this form of aggression. There was an improvement in concentration, no lessening of drive, and no evidence of anergia. The relief occurred within three weeks of commencing treatment. No anticholinergic drugs were required. Naturally, they were happier people and their rapport with friends and family improved.

I lay no claim to having found a universal panacea for aggressive behaviour but the straws in the wind do seem to indicate that there is a place for the use of this drug or its oral form, flupenthixol dihydrochloride, outside the treatment of the schizophrenias. I would be very interested to hear if others using this drug have noted any like reaction. -I am, etc.,

Winwick Hospital,

P. M. O'Flanagan Warrington, Cheshire

\section{Measurement of Side Effects of Drugs}

SIR,-Drs. E. C. Huskisson and J. A. Wojtulewski (29 June, p. 698) suggest that when assessing the proportion of patients with side effects from drug therapy the interviewing doctor should not consult a check list. They found that direct questioning increases the number of positive responses in a group not receiving the treatment and reduces the number of positive responses to questions not on the check list.

They suggest that the doctor should ask, "Have you noticed any new symptoms which might be related to the treatment?" This method of collecting information suffers from a lack of standardization. The exact que tion asked may vary, and the "sympathetic" doctor receives more positive responses. The results thus obtained may not be reproduced by another observer, and may account for the wide variation in the prevalence of side effects reported in different publications. An example is given by methyldopa and sleepiness. In well-designed and conducted studies the proportion complaining of sleepiness while taking this drug varies between $12 \%{ }^{1}$ and $83 \% .^{2}$ Research workers investigating symptoms and side effects reauire to know the prevalence of these complaints in the general population 
and a control treatment group. This will not mask a drug effect in a treatment group but will permit a more precise estimate of the number of patients in whom the symptom is due to a particular drug.

How can the standardization of symptom reporting be achieved? In my opinion the doctor must not ask verbal auestions but should devise a questionnaire which is completed by the patient. He must ensure that the written questions are understood by the patients, that the questions are completed, and that the questionnaire is returned by a high proportion of patients. Similarly, in a non-treated group the repeatability of the answers (positive or negative) should be tested.

Continuing the example above, a selfadministered questionnaire found that $56 \%$ of patients on methyldopa complained of sleepiness $^{3}$ against $31 \%$ in the general population. ${ }^{4}$ By using such questionnaires the results should be reproducible and the side effects of new therapeutic agents (when evaluated by the same techniques) may be referred back to the known and validated control data.-I am, etc.,

\section{J. BULPITT}

Chronic Disease Control Study Unit, London School of Hygiene and Tropical Medicine,

1 Amery. A., et al., British Medical fournal, 1970, 4. 392.

2 Pritchard, B. N. C., et al., British Medical Fournal, 1968, 1, 135 .

Bulpitt, C. J., and Doilery, C. T., British Medical Fournal. 1973, 3. 485. Fournal of C. Dronic Diseases. In press.

SIR,-I would agree with Drs. E. C. Huskisson and J. A. Wojtuleuski (29 June, p. 698) that the use of a check list of side effects during clinical trials biases both the observer and the patient. One use of a check list which they do not mention, however, is during the pre-trial assessment of the patients. It has been my custom for some years $^{1}$ to use a check list of common symptoms particularly relating to the gastrointestinal and nervous systems. These are recorded as being present frequently, occasionally, or never. I subseauently use a general question such as "Have the tablets upcet you in any way?" and during the final analvsis relate the answers to the pre-trial check list. This is of particular importance in trials in rheumatoid arthritis, where a period on placebo therapy may be considered unethical $^{2}$ so that the comparicons are between two active treatments with no untreated period available for enumeration of "placebo" side effects.-I am, etc.,

IAN HASLOCK

Rheumatology Unit,

Middilechrough General Hospital,

1 Haslock, D. I., Nicholson, P. A., and Wright, V.,

Clinical Trials fournal. 1971, 8, 43 . 1973, 12, Suppl., p. 54

\section{Vitamin $\mathbf{E}$ in Thalassaemia}

SIR,-Your excellent leading article (22 June, p. 625) directs attention to vitamin $E$, this time as a possible aetiological factor in thalassaemia and other haemolytic states.
Since there are few drugs for which more extravagant claims have been made on flimsier grounds may we amplify some of your comments?

There is no doubt that vitamin $\mathrm{E}$ is a powerful antioxidant in vitro. There is no doubt that the susceptibility of red blood cells to autoxidation is much increased in thalassaemia major and in many other haemolytic states. It is uncertain whether in thalassaemia this is a cause or a consequence of the red cell abnormality. It is plausible but almost certainly untrue that it is in any way related to vitamin $\mathrm{E}$ deficiency. We have treated a number of children with thalassaemia with large doses of vitamin $E$ for periods up to a year. We hope eventually to publish our findings in detail but our provisional conclusions can be briefly stated. It is comparatively simple in this condition to raise serum vitamin $E$ levels to normal by oral medication. It is possible to reduce red cell malonyldialdehyde (MDA) (that is, the in-vitro susceptibility of the cells to autoxidation) to near normal. There is little to suggest that either change has any effect on the haemoglobin pattern or on blood transfusion requirements.

This is not perhaps altogether surprising in the light of recent experimental work. It has long been known that plasma is a powerful antioxidant, and its antioxidant potency can be measured. ${ }^{1-4}$ Fractionation has shown that vitamin $\mathrm{E}$ contributes only marginally to this activity, which is largely a function of two protein fractions. One fraction contains caeruloplarmin, and its mode of action is still uncertain. The second is transferrin, and its antioxidant potency is almost certainly a direct expression of its ironbinding capacity. The key role of iron and of iron binding in lipid autoxidation and antioxidant protection respectively points back to vitamin $\mathrm{E}$ as a possible diagnostic tool. Though, in our experience, the serum level of the vitamin bears no relation to the severity of the haemolysis it does seem to

\section{Community Medicine-a Disclaimer}

SIR,-No doctor acquainted with the starved resources of so many departments of an average district general ho'pital can fail to sympathize with the cry from the heart of "Consultant Radiologist" exclaimed in his Personal View (6 July, p. 38)

What worries me is that his justifiable frustration is laid at the door of community medicine, particularly at this very time when its practitioners are engaged upon the task of endeavouring to demonstrate the true potential of injecting the preventive medicine concept into the whole of the Health Service and of strengthening the resources of the primary medical care teams-currently no less starved than the hospitals - to the better fulfilment of that greater part of medical care which will always fall to be undertaken outside the hospitals.

There are D.H.S.S. circulars which define subtle differences between the work of community physicians and specialists in community medicine, but the fact is that the term "specialist in community medicine" is a generic one, which for reasons of career and training embraces those medical administrators on the staff of regional health authorities who have to continue the un- correlate with the severity of the iron overcoading.

Before discounting vitamin $\mathrm{E}$ as an aetiological factor in thalassaemia we would make two provisos. Firstly, though the increased susceptibility of thalassaemic red cells to autoxidation appears to be the result rather than the cause of the red cell abnormality this is not necessarily true of other haemolytic states. In particular the haemolytic thrombocytopenic syndrome of premature infants described by Oski and Barness ${ }^{5}$ and others almost certainly reflects oxidative damage. (It is also the only syndrome in man which can be attributed with reasonable certainty to vitamin $\mathrm{E}$ deficiency.) Secondly, the fact that vitamin $\mathbf{E}$ deficiency probably plays no causative role in thalassaemia does not mean that, given in pharmacological doses, the vitamin could have no beneficial action. In fact circumstantial and still very incomplete evidence suggests that it might mitigate the effects of iron overloading. The difficulty is that thalassaemia is an extremely heterogeneous disease and iron toxicity is particularly difficult to assess. One is, moreover, dealing with a drug which is being currently promoted for conditions ranging from varicose ulcers through loss of sexual vigour to cancer and old age. The answer clearly requires a carefully controlled-that is, long-term-and properly co-ordinated clinical or laboratory trial or both.-We are, etc.,

C. B. MODELL J. STOCKS T. L. DORMANDY

Department of Chemical Pathology,

Whittington Hospital,

Barber, A. A., Archives of Biochemistry and

Bioohysics, 1961, 92, 38. 36. 61

orks, J., et al., Clinical Science and Molecular

Medicine, 1974, 47. In press.

tocks. J., et al., Clinical Science and Molecular Medicine, 1947, 47. In press.
Oski, F.

Pediatrics, 1967, 70, 211.

enviable task, formerly undertaken by senior medical officers on the staff of S.A.M.O.s, of dividing up the regional cake of medical manpower and resources between the understandable but currently unattainable desires of the clinical consultants.

Such work, albeit necessary, is scarcely representative of the essence of the emerging specialty of community medicine, which requires such careful nurture during its infancy. It is in no way to disown our hardpressed colleagues holding such appointments to suggest to regional medical officers that the official description "specialist in community medicine" be tucked away in the personal files and that some more specifically descriptive title be adopted for day-to-day use.

Finally, one cannot let pass without disillusion "Consultant Radiologist's" vision of the specialist in community medicine enthroned at the apex of his vast managerial pyramid. Nothing could be further from the truth. Former medical officers of health who had built up carefully trained teams of medical and administrative staff, capable of fulfilling necessary services for the community, now find themselves naked, bereft, 